\title{
Spatial prediction of the risk of exposure to Echinococcus spp. among schoolchildren and dogs in Ningxia Hui Autonomous Region, People's Republic of China
}

\author{
Angela M. Cadavid Restrepo, ${ }^{1}$ Yu Rong Yang, ${ }^{2,3}$ Donald P. McManus, ${ }^{3}$ Darren J. Gray,, 3 \\ Tamsin S. Barnes, ${ }^{4,5}$ Gail M. Williams, ${ }^{6}$ Ricardo J. Soares Magalhães, ${ }^{4,7}$ Archie C.A. Clements ${ }^{1}$ \\ ${ }^{1}$ Research School of Population Health, Australian National University, Canberra, Australia; ${ }^{2}$ Ningxia \\ Medical University, Xingqing, Yinchuan, China; ${ }^{3}$ Molecular Parasitology Laboratory, QIMR Berghofer \\ Medical Research Institute, Brisbane, Australia; ${ }^{4}$ School of Veterinary Science, University of Queensland, \\ Gatton, Australia; ${ }^{5}$ Queensland Alliance for Agriculture and Food Innovation, University of Queensland, \\ Gatton, Australia; ${ }^{6}$ School of Public Health, University of Queensland, Brisbane, Australia; ${ }^{7}$ Children's \\ Health and Environment Programme, Queensland Children's Medical Research Institute, University of \\ Queensland, Brisbane, Australia
}

\begin{abstract}
The geographical distribution of Echinococcus spp. infections in Ningxia Hui Autonomous Region (NHAR) has been reported to be expanding in response to environmental change. The aim of the
\end{abstract}

\footnotetext{
Correspondence: Angela M. Cadavid Restrepo, Research School of Population Health, Australian National University, Building 62 Mills Road, Canberra, New South Wales, Australia.

Tel.: +61.2.612.52741 - Fax: +61.261250733.

E-mail: angela.cadavid@anu.edu.au
}

Key words: Echinococcus granulosus; Echinococcus multilocularis; Environment; Geographic information systems; Ningxia Hui Autonomous region; China.

Contributions: AMCR and ACAC designed the study; AMCR and YRY collected, standardised and geo-referenced the clinical and environmental data; AMCR and ACAC developed the models with input from RJSM; ACAC, YRY, DPM, DJG, RJSM, TSB, GMW provided critical comments and helped in drafting the manuscript. AMCR and ACAC finalised the manuscript. All authors read and approved the final manuscript.

Conflict of interest: the authors declare no potential conflict of interest.

Funding: the authors acknowledge financial support by the National Health and Medical Research Council (NHMRC) of Australia (APP1009539).

Ethical approval: the protocol for this study was reviewed and approved by the Human and Animal Research Ethics Committees of the Ningxia Medical University, QIMR Berghofer Medical Research Institute, and the Human Ethics Committee of The Australian National University. After explaining the purpose and procedures of the surveys, parents or adult representatives of the students and dog owners who agreed to participate were asked to sign an informed written consent form.

Received for publication: 8 November 2017.

Revision received: 13 February 2018.

Accepted for publication: 13 February 2018.

(C) Copyright A.M. Cadavid Restrepo et al., 2018

Licensee PAGEPress, Italy

Geospatial Health 2018; 13:644

doi:10.4081/gh.2018.644 present study was to predict and compare the spatial distribution of human seropositivity for Echinococcus granulosus and Echinococcus multilocularis and infections with these parasites in dogs in four counties in the south of NHAR to identify communities where targeted prevention and control efforts are required. Predicted seroprevalence of E. granulosus in schoolchildren and E. granulosus infections in dogs concurred spatially, whereas predicted seroprevalence of $E$. multilocularis in schoolchildren and E. multilocularis infections in dogs differed spatially. Enhanced vegetation index was significantly associated with $E$. multilocularis seropositivity among schoolchildren, and infections with $E$. granulosus and E. multilocularis in dogs. A positive association was also found between dog infection with E. granulosus and cultivated land, and a negative association between human seropositivity for E. granulosus and bare-land/artificial surfaces. The findings of this study support the importance of land cover and climatic variables in determining habitat suitability for Echinococcus spp. infections, and suggest that definitive hosts other than dogs (e.g. foxes) are important in defining the geographical risk of human seropositivity for E. multilocularis in NHAR.

\section{Introduction}

Cystic echinococcosis (CE), caused predominantly by infection with Echinococcus granulosus, and alveolar echinococcosis (AE), due to infection with E. multilocularis, have long incubation periods (5-15 years) that delay diagnosis and treatment (Ammann and Eckert, 1996), and require long-term monitoring and medical care for most patients (Brunetti et al., 2011; Kern et al., 2017). It is estimated that 188,000 people are infected with E. granulosus globally every year which represents a human health burden of 184,000 disability-adjusted life years (DALYs) lost (Torgerson et al., 2015). An estimate of 18,235 cases of AE occur annually resulting in a loss of approximately 666,433 DALYs (Torgerson et al., 2010). From these figures, $91 \%$ of the total number of cases and $95 \%$ of the disease burden of AE are estimated to be in the People's Republic of China (PR China) (Torgerson et al., 2010).

The transmission of E. granulosus and E. multilocularis in domestic and sylvatic life cycles, respectively, is maintained by a wide range of intermediate and definitive hosts (Romig et al., 
2017). The transmission of E. granulosus involves domestic dogs and other canids as typical definitive hosts, and sheep and other ungulates as intermediate hosts (Eckert and Deplazes 2004). E. multilocularis is transmitted within predator-prey cycles that involve different species of foxes as main definitive hosts and small mammals as intermediate hosts (Eckert and Deplazes, 2004; Kapel et al., 2006). Domestic dogs are susceptible to infection with both parasites, and are currently regarded as significant hosts for $E$. granulosus and E. multilocularis (Moss et al., 2013; Rausch, 1995). In Gansu Province and the eastern Tibetan plateau, PR China, particularly, domestic dogs have been identified as the main transmission source of both parasites to the local human population (Craig et al., 2000; Wang et al., 2010). Comprehensive reviews of the life cycles of E. granulosus and E. multilocularis, clinical manifestations of human echinococcoses, diagnosis, treatment, prevention and control are available (Craig et al., 2017; Kern et al., 2017; Romig et al., 2017).

$\mathrm{CE}$ and $\mathrm{AE}$ are characterised by great variation in their geographical distributions, with important differences at regional and local spatial scales (Cringoli et al., 2007; Eckert, 2001; Giraudoux et al., 2006; Giraudoux et al., 2013a; Mastin et al., 2011). CE has a widespread global distribution with the highest disease burden in poor pastoralist communities, whilst AE occurs within defined areas of temperate and subarctic regions of the northern hemisphere (Deplazes et al., 2017). Various socio-demographic, economic and environmental factors that act at different spatial scales have been found to be associated with the distributions of CE and AE risk (Atkinson et al., 2013; Cadavid Restrepo et al., 2015; Danson et al., 2003; Giraudoux et al., 2007). These factors determine the population dynamics and behaviour of the hosts, predator-prey interactions and the survival and development of the parasites.

Land cover change factors have been found to be linked to the distribution and dynamics of E. multilocularis intermediate hosts (Raoul et al., 2008; Silva et al., 2005). Deforestation (Giraudoux et al., 1998; Giraudoux et al., 2003), afforestation (Raoul et al., 2008), and specific farming and fencing practices (Raoul et al., 2006; Wang et al., 2004) have been shown to modify the distribution of various species of small mammals. Overgrazing and low grass height were also linked positively to the presence and abundance of intermediate hosts for E. multilocularis in highly endemic areas on the Tibetan Plateau (Raoul et al., 2006; Wang et al., 2010), while enhanced vegetation index (EVI) had a negative association with the presence of Ochotona curzoniae (plateau pika) and Ochotona cansus (Gansu pika), key intermediate hosts for the parasite in Serxu County, Sichuan Province (Marston et al., 2016). To date, surprisingly few studies have been conducted to investigate the host-environment interactions that regulate the domestic life cycle of E. granulosus (Eckert and Deplazes, 2004).

Spatial epidemiological approaches that integrate the use of geographical information systems (GIS), remote sensing and model-based geostatistics serve as valuable analytical tools to quantify and predict the spatial heterogeneities in the risk of echinococcoses across different spatial scales (Cadavid Restrepo et al., 2015). Because control interventions against $\mathrm{CE}$ and $\mathrm{AE}$ require a long period of implementation in order to be successful, the outcome of spatial epidemiological approaches may help define national and regional policies to reduce the burden of these diseases, and also to prioritise areas where interventions are required (Cadavid Restrepo et al., 2015; Craig et al., 2017).

Nine valid species are currently recognised within the genus
Echinococcus: E. granulosus, E. multilocularis, E. ortleppi, E. canadensis, E. oligarthrus, E. vogeli, E. shiquicus, E. felidis, E. equinus. E. granulosus and E. multilocularis are the species found in Ningxia Hui Autonomous Region (NHAR) (McManus et al., 1994; Yang et al., 2005). A spatial prediction study of E. multilocularis in Xiji county, south of NHAR found that $E$. multilocularis transmission was determined by landscape factors, such as presence of lowland pasture (Pleydell et al., 2008). It was also suggested that the infection did not occur primarily through arvicolines species which are key intermediate hosts for this parasite in other areas (Pleydell et al., 2008). In this study, we extend the previous work that was undertaken in Xiji County to encompass three additional neighbouring counties, Haiyuan, Guyuan and Tongxin, located in the south of NHAR. Using Bayesian modelbased geostatistics, we aimed to create spatial predictions of the risk of human seropositivity for E. granulosus and E. multilocularis, and the risk of dog infections with these parasites. In the present study, the term human exposure was meant to signify that children harboured possibly the metacestode stage of E. granulosus and/or E. multilocularis, whether or not, they had clinical, serological or ultrasound evidence of active cysts (based on the description of a possible echinococcosis case suggested elsewhere (Brunetti et al., 2010). These maps can guide decision-makers to spatially target echinococcosis control interventions.

\section{Materials and Methods}

\section{Study area}

The surveys were conducted in four contiguous counties of NHAR, Xiji, Haiyuan, Guyuan and Tongxin Counties, which are located in the south of the Autonomous Region between latitudes $35^{\circ} 33^{\prime}-36^{\circ} 98^{\prime} \mathrm{N}$, and between longitudes $105^{\circ} 64^{\prime}-106^{\circ} 24 \mathrm{E}$. The four counties together cover an area of approximately $21,557 \mathrm{~km}^{2}$. Based on the estimates of the national census in 2015, the total populations were, 344,045 in Xiji, 396,938 in Haiyuan, 1,211,789 Guyuan and 325,441 in Tongxin, of whom 58.0\%, 70.8\%, 46.1\% and $86.1 \%$ were of the Hui Islamic ethnic minority, respectively, while almost all others were Han Chinese (National Bureau of Statistics of China 2015) (Figure 1).

The counties lie in a temperate continental monsoon climate zone that is characterized by four distinct seasons. The annual average temperature is $5.37{ }^{\circ} \mathrm{C}$ and the average annual precipitation is $418.2 \mathrm{~mm}$. Approximately $60 \%$ of the precipitation is in the form of rainstorms that take place during the rainy season, from June to September. Elevation ranges from 1500 to 2800 meters above sea level. The geography of this part of NHAR include mountainous areas around Mt. Liupan, and the Loess hills. Vegetation varies from forest mainly in the southeast to slope farmland that accounts for most of the cultivated land, and to desert in the northeast and northwest.

\section{Data on seroprevalence of $\boldsymbol{E}$. granulosus and E. multilocularis}

Data on the seroprevalence of E. granulosus and E. multilocularis were obtained from a cross-sectional school-based survey conducted across the four counties in 2012-2013. Children aged 618 years were selected to ensure that the collected data were representative of recent exposure risk (as adults might have been 
exposed over a long duration in the past). A geostatistical design (grid plus close pairs) was used to select the schools for the survey (Diggle and Ribeiro 2007). A $15 \times 15 \mathrm{~km}$ grid was created and overlaid on the entire study area using ArcGIS software version 10.3.1 (ESRI 2015). The primary set of schools selected for the survey consisted of those schools located in closest proximity to the grid nodes. A second set of schools was also selected comprising schools located in near proximity to those selected at the nodes of the grid (the close pairs). The origin of the grid, the distance and direction of the close pairs from the primary set, and the primary subset for which close pairs were selected, were generated using a random number generator. This approach was used because it has been identified as the most efficient survey design for estimating spatial variability in environmental variables (Diggle and Ribeiro, 2007).

All children who agreed to participate in the survey were first assembled and asked to provide demographic and exposure information using standardised questionnaires that were administered by the school teachers. Then, a blood sample from the ear lobe was collected from participants for specific antibody testing by enzyme linked immunosorbent assay (ELISA) using E. granulosus cyst fluid antigen B and E. multilocularis crude protoscolex extract (Craig et al., 1992; Yang et al., 2008). EgB and EmP ELISA sensitivity is $>85 \%$ for $\mathrm{CE}$ and $>90 \%$ for $\mathrm{AE}$, respectively (Bartholomot et al., 2002; Craig et al., 1992; Craig et al., 2000). Specificity is from $70 \%$ to $100 \%$ for CE (Carmena et al., 2006) and $87 \%$ for AE (Bartholomot et al., 2002). Finally, abdominal ultrasound was used to screen schoolchildren and detect and classify early CE and/or AE cysts. The classification scheme of CE and AE proposed by the World Health Organization was used to categorise
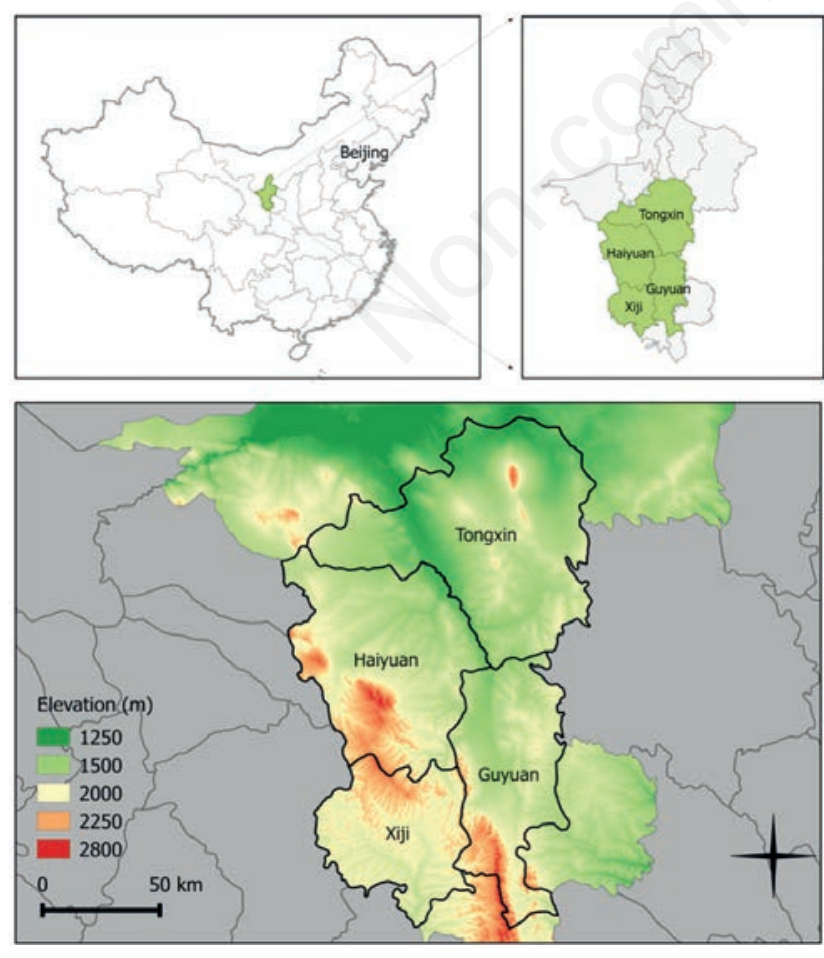

Figure 1. Map and elevation of Xiji, Haiyuan, Guyuan and Tongxin counties and location of NHAR within China. the hepatic lesions (Kern et al., 2006; WHO Informal Working Group 2003; WHO Informal Working Group on Echinococcosis 2001). Although ultrasound is the method of choice to confirm human echinococcoses, it has low sensitivity to detect small cysts (McManus et al., 2012). Therefore, due to the young age of participants and the slow rate of growth of the cysts, the results of the ultrasound are not reported here. Schoolchildren, who were screenpositive for one of the infections or both, were referred to the local medical centre for free treatment.

\section{Data on dog infection}

Faecal samples were collected from dogs presenting to the veterinary centre nearest to the selected schools, including rural and urban locations, between 2012 and 2013. The faecal samples were initially stored separately for at least 7 days at $-80{ }^{\circ} \mathrm{C}$ to inactivate the parasite eggs, and then transferred to a $-20{ }^{\circ} \mathrm{C}$ freezer. The processing and copro-analysis were conducted at the Zoonoses Laboratory of the Ministry of Agriculture in the Lanzhou Veterinary Research Institute, Gansu Province, PR China. A Multiplex polymerase chain reaction (PCR) assay was used for simultaneous detection of E. granulosus and E. multilocularis DNA (Liu et al., 2015). The geographic coordinates of each school and veterinary centre were collected using a hand-held global positioning system. Maps of the surveyed locations is available (Figure 2).

\section{Environmental and remotely sensed data}

Land cover maps at a 30-meter spatial resolution for the years 2005, 2010 and 2015 were obtained from a previous study that assessed and quantified land cover change in NHAR between 1991 and 2015 (Cadavid Restrepo et al., 2017). The maps were created using time series images retrieved from the Landsat Surface Reflectance Climate Data Record available in Earth Explorer (The United States Geological Survey, USGS). Seven land cover categories were initially identified: water bodies, artificial surfaces, bare or sparsely vegetated areas, herbaceous vegetation, cultivated land, scrubland and forest (Table 1). However, due to significant spectral confusion between artificial surfaces and bare or sparsely vegetated areas, these land cover classes were merged and represented as a single category in the maps and further analyses. Details of the process of land cover classification and accuracy assessment are provided elsewhere (Cadavid Restrepo et al., 2017).

Landsat 30-meter enhanced vegetation index (EVI) data were extracted from the Earth Resources Observation and Science (EROS) Center Science Processing Architecture (ESPA) On Demand Interface. Data were downloaded from a month during the growing season in NHAR (June-November) for the years 2008 and 2012. However, when there were no data available for the specified time period, the closest-in-time EVI estimates were retrieved for the analyses.

Elevation estimates were obtained in a GeoTIFF format at the spatial resolution of 1 arc-second (approximately $30 \mathrm{~m}$ ) from the Advanced Spaceborne Thermal Emission and Reflection Radiometer (ASTER) Global Digital Elevation Model (GDEM) version 2 (The National Aeronautics and Space Administration (NASA) and Ministry of Economy Trade and Industry (METI)). The ASTER GDEM was downloaded from the Earth Explorerwebsite.

Average monthly values of temperature and precipitation for the period January 1, 2008 to December 31, 2013 were provided by the Chinese Academy of Sciences in a raster format at the spa- 
tial resolution of $1 \mathrm{~km}$. The monthly climate values had first been collected from 16 local weather stations and then interpolated using the Inverse Distance Weighting (IDW) method.

A boundary map of the four counties was downloaded from the DIVA-GIS website (DIVA GIS). The geo-referenced data sets that included the locations of the surveyed schools and veterinary centres were imported into ArcGIS and projected to the Universal Transverse Mercator (UTM) coordinate system zone 48N. ArcGIS was used to delineate $1 \mathrm{~km}$ and $5 \mathrm{~km}$ radii buffer zones around the centres of the survey site locations and all covariates were summary estimates extracted from these buffer zones. The buffer sizes were selected in order to examine areas of environmental conditions that provide suitable habitat for the parasite hosts. Land cover variables were summarized as percentages of each land cover type within the buffer zones for the years 2005, 2010 and 2015. The extracted estimates were then used to calculate change rates for the periods 2005-2010, and 2010-2015. In this way, it was possible to estimate the spatial extent of all land cover classes by buffer area for the years 2008 and 2012. For climate, elevation and EVI variables, a moving 5-year average (MA) of the values of the independent variables was generated for the period 2008-2012 to examine the host/environment interplay over an extended period of time rather than at a single point. For each surveyed location, the data extracted included: annual, summer (June, July and August) and winter (December, January and February) weighted average temperature and precipitation, and spatial mean values of EVI and elevation within the buffer zone.

\section{Variable selection}

Using R software version 3.2.2. (R Core Team 2015), non-spatial univariate binomial logistic regression models were developed to examine the association between the environmental variables with E. granulosus and E. multilocularis infections in humans and dogs. Spearman correlation analyses were conducted to assess collinearity among all independent variables. If the correlation coefficient between a pair of covariates was $>0.9$, the covariate with the highest value of Akaike Information Criterion (AIC) in the univariate regression models was excluded. Various non-spatial binomial multivariate logistic regression models were also created to compare differences in model fit. Multivariate logistic regression models were also developed for human and dog infections and for each species. The models with the lowest AIC were selected for subsequent geostatistical analyses. Nonlinear associations between the environmental covariates and the infections were modelled using quadratic terms.

\section{Model-based geostatistics}

Separate multivariable geostatistical logistic regression models were created in a Bayesian framework for human serological status and dog infections with each parasite species using the OpenBUGS software 3.2.3 rev 1012 (Members of OpenBUGS Project Management Group 2014). First, Bayesian geostatistical models were developed with the explanatory variables as fixedeffects but without considering the spatial dependence structure of the data. Then, Bayesian geostatistical models for each infection were created including the explanatory variables and a spatially structured random effect.

The fit of the models was compared using the deviance information criterion (DIC), where low DIC values indicate a better fit. Statistical significance of the covariates in the models was deemed to be achieved if the $95 \%$ credible intervals $(95 \% \mathrm{CrI})$ of the estimated odds ratios (OR) excluded 1.

For all infections, the best-fit model was the one that included the spatial random effect. Assuming a Bernoulli-distributed dependent variable, $Y_{i j}$, corresponding to the serological/infection status $(0=$ seronegative/noninfected, $1=$ seropositive/infected $)$ of an individual $i$ in location $j$, the model structures for schoolchildren (formula 1) and dogs, (formula 2), were as follows:

$$
\begin{gathered}
Y_{i j} \sim \operatorname{Bern}\left(p_{i j}\right) \\
\operatorname{logit}\left(p_{i j}\right)=\alpha+\gamma \times \operatorname{age}_{i}+\sum_{z=1}^{z} \beta_{z} \times \lambda_{z j}+s_{j}
\end{gathered}
$$

\begin{tabular}{|c|c|c|c|}
\hline Code & Land cover & Description & Content \\
\hline 1 & Water bodies & All areas of water & Streams and canals, lakes, reservoirs, bays and estuaries \\
\hline 2 & Artificial surfaces & Land modified by human activities & $\begin{array}{l}\text { Residential areas, industrial and commercial complexes, } \\
\text { transport infrastructure, communications and utilities, } \\
\text { mixed urban or built-up land and other built-up land }\end{array}$ \\
\hline 3 & Bare or sparsely vegetated areas & Areas with little or no green vegetation present & $\begin{array}{l}\text { Dry salt flats, sandy areas, bared exposed rock } \\
\text { and mixed barren land }\end{array}$ \\
\hline 4 & Herbaceous vegetation & $\begin{array}{l}\text { Areas characterized by natural or } \\
\text { semi-natural vegetation }\end{array}$ & Grasses and forbs \\
\hline 5 & Cultivated land & $\begin{array}{l}\text { Areas where the natural vegetation has been } \\
\text { emoved/modified and replaced by other types } \\
\text { of vegetative cover that have been planted } \\
\text { for specific purposes such as food, } \\
\text { feed and gardening }\end{array}$ & $\begin{array}{l}\text { Cropland and pasture, orchards, groves, vineyards, nurseries } \\
\text { and ornamental horticultural, other cultivated land }\end{array}$ \\
\hline 6 & Scrubland & $\begin{array}{l}\text { Natural or semi-natural woody vegetation } \\
\text { with aerial stems }<6 \mathrm{~m} \text { tall }\end{array}$ & $\begin{array}{l}\text { Evergreen and deciduous species of true shrubs and trees } \\
\text { or shrubs that are small or stunted }\end{array}$ \\
\hline 7 & Forest & $\begin{array}{l}\text { Areas characterized by tree cover or } \\
\text { semi-natural woody vegetation greater } \\
\text { than }<6 \mathrm{~m} \text { tall }\end{array}$ & Deciduous forest, evergreen forest and mixed forest \\
\hline
\end{tabular}

Table 1. Land cover classification scheme and definitions. 


$$
\begin{gathered}
Y_{i j} \sim \operatorname{Bern}\left(p_{i j}\right) \\
\operatorname{ogit}\left(p_{i j}\right)=\alpha+\sum_{z=1}^{z} \beta_{z} \times \lambda_{z j}+s_{j}
\end{gathered}
$$

where $\alpha$ is the intercept, $\gamma$ is the coefficient for age, $\beta$ is a matrix of $\mathrm{z}$ coefficients, $\lambda$ is a matrix of $\mathrm{z}$ environmental variables, and $s_{j}$ a geostatistical random effect. The correlation structure of the geostatistical random effect was assumed to be an exponential function of the distance between points:

$$
f\left(d_{k l} ; \phi\right)=\exp \left[-\phi d_{k l}\right]
$$

where $d_{k l}$ are the distances between pairs of points $k$ and $l$, and $\phi$ is the rate of decline of spatial correlation per unit of distance. A normal distribution was used for the priors for the intercept and the coefficients (mean $=0$ and precision, the inverse of variance, $=1$ $\times 10^{-3}$ ), whereas a uniform distribution was specified for $\phi$ (with upper and lower bounds $s=0.01$ and 100 ; the lower bound set to ensure spatial correlation at the maximum separating distance between survey locations was $<0.5$ ). A non-informative gamma distribution was used to specify the priors for the precision (shape and scale parameters $=0.001,0.001$ ).

A burn-in of 1000 iterations was run first and discarded. Sets of 20,000 iterations were then run and examined for convergence. Convergence was assessed by visual inspection of history and density plots and by examining autocorrelation of the model parameters. Because autocorrelation was observed for most variables, thinning was applied by storing every 10th iteration. In each model, convergence was achieved for all variables at approximately 80,000 iterations. The last 10,000 values from the posterior distributions of each model parameter were recorded. The rate of decay of spatial correlation between locations $(\phi)$ with distance and the variance of the spatial structured random effect $\left(\sigma^{2}\right)$ were also stored. To define the prediction locations, a regular $5 \mathrm{~km} \times 5$ $\mathrm{km}$ grid was overlaid over the entire study territory. The risk of human seropositivity and dog infection at the prediction locations was estimated using the spatial.unipred function in OpenBUGS. The function applies the model equation at each non-sampled location using the covariates values extracted for them and the separating distance between those locations and the surveyed locations.

Maps that represent the posterior distributions of predicted seroprevalence of these parasite species in humans and predicted prevalence of both infections in dogs were created in ArcGIS for the four counties.

\section{Results}

\section{Sample description}

The final data set of the surveyed schools consisted of 106 locations and a total of 7547 schoolchildren who were screened for Echinococcus spp. seropositivity. Haiyuan (64.5\%) and Xiji $(54.0 \%)$ were the two counties with the highest observed overall seroprevalence of both infections, followed by Guyuan $(43.3 \%)$ and then by Tongxin (24.6\%). The seroprevalence of E. granulosus among schoolchildren by county was higher (45.6\%) in Xiji, while a higher seroprevalence of E. multilocularis was observed in Haiyuan $(21.1 \%)$ (Table 2). The mean age of participants who were seropositive for E. granulosus was 11.4 years (median: 11, standard deviation (SD): 2.6), and the mean age for those who were seropositive for E. multilocularis was 11.3 years (median: 13, SD: 2.5).

The final data set of the survey conducted in the veterinary centres included 111 locations and a total of 3,324 dogs. The county with the highest overall prevalence of dogs infected with each of the parasite species, E. granulosus and E. multilocularis, was Xiji County (16.5\% and $14.2 \%$, respectively). The prevalence rates of dog infection with E. granulosus in the other three counties were $12.0 \%, 11.8 \%$ and $9.5 \%$ in Tongxin, Haiyuan and Guyuan, respectively. The prevalence of dog infection with E. multilocularis were notably lower in Haiyuan (3.4\%), Tongxin (1.6\%) and Guyuan (1.5\%) compared with Xiji (Table 2).

Figure 2 shows the observed spatial distributions of the prevalence of the infections in humans and dogs by parasite species and locations. From the maps, it is difficult to identify a clear geographical pattern. However, the maps confirm that seropositivity for E. granulosus was more widespread than the seropositivity for E. multilocularis in the study areas.

\section{Models of $\boldsymbol{E}$. granulosus and $\boldsymbol{E}$. multilocularis seroposi- tivity in schoolchildren}

The DICs of the models of seropositivity for E. granulosus

Table 2. Seroprevalence of human seropositivity for E. granulosus and $E$. multilocularis and dog infections by county.

\begin{tabular}{lccccc} 
& \multicolumn{2}{c}{ E. granulosus } & \multicolumn{2}{c}{ E. multilocullaris } & \\
& Positive & Negative & Positive & Negative & Total \\
Xiji & $765(45.6 \%)$ & $912(54.4 \%)$ & $141(8.4 \%)$ & $1,536(91.6 \%)$ & $1,677(100 \%)$ \\
Guyuan & $601(36.4 \%)$ & $1,051(63.6 \%)$ & $114(6.9 \%)$ & $1,538(93.1 \%)$ & $1,652(100 \%)$ \\
\hline Haiyuan & $842(43.4 \%)$ & $1,099(56.6 \%)$ & $409(21.1 \%)$ & $1,532(78.9 \%)$ & $1,941(100 \%)$ \\
Tongxin & $523(22.9 \%)$ & $1,754(77.1 \%)$ & $39(1.7 \%)$ & $2,238(98.3 \%)$ & $2,277(100 \%)$ \\
\hline Xiji & & & Dogs & & $750(100 \%)$ \\
Guyuan & $124(16.5 \%)$ & $626(83.5 \%)$ & $106(14.1 \%)$ & $644(85.9 \%)$ & $660(100 \%)$ \\
\hline Haiyuan & $63(9.5 \%)$ & $597(90.5 \%)$ & $10(1.5 \%)$ & $650(98.5 \%)$ & $771(100 \%)$ \\
Tongxin & $91(11.8 \%)$ & $680(88.2 \%)$ & $26(3.4 \%)$ & $745(96.6 \%)$ & $1,143(100 \%)$ \\
\hline
\end{tabular}

Cross-sectional surveys conducted in schools and veterinary centres in 2012-2013. 
with and without accounting for spatial correlation were 8,699 and 8,903 , respectively. In the spatial model, bare-land/artificial surface land cover class, was the only variable that had a statistically significant association with seropositivity. The estimated decrease in seropositivity was $0.9 \%$ (95\% CrI: $0.04 \%-1.8 \%)$ for an increase of $1 \%$ in the extent of bare-land/artificial surfaces (Table 3). The $E$. multilocularis model with the spatial component had a DIC of 3,575, while the model without the spatial component had a DIC of 3,667 . In the spatial model, EVI had a significant positive association with seropositivity for E. multilocularis. There was an estimated increase of $0.2 \%$ (95\% CrI: $0.1 \%-0.3 \%)$ in seropositivity for E. multilocularis for 1-unit increase in EVI within the 5-km buffer area at a 5-year lag. Additionally, the quadratic terms for winter and summer temperature in the 5-km buffers were statistically significant in the 5 years prior to the survey, indicating a significant nonlinear association (Table 4).

The variance of the spatially structured random effect was 0.6 (0.4 to 1.0) in the model of seropositivity for E. granulosus and 1.2 ( 0.7 to 1.9 ) in the model of seropositivity for E. multilocularis. These estimates imply that, after accounting for the effect of the statistically significant variables, the residual spatial variation was higher for human seropositivity for E. multilocularis. Phi $(\phi)$, that is the rate of decay of spatial correlation (with bigger $\phi$ indicating smaller clusters), was 20.9 in the E. granulosus model and 45.2 in the E. multilocularis model. This means that, after accounting for the effect of covariates, the radii of the clusters were larger for human seropositivity for E. multilocularis than for human seropositivity for E. granulosus.

The models of dog infection with E. granulosus with the spatial component had a lower DIC, 2.121, compared with the one without the spatial component, 2250. There was an increase of $2.0 \%$ (95\% CrI: $0.8-3.3 \%$ ) in the prevalence of dog infection with E. granulosus for a $1 \%$ increase in the coverage of cultivated land, and $0.05 \%$ (95\% CrI: $0.001-0.1 \%$ ) for an increase of 1 unit of EVI (Table 5). The spatial model for E. multilocularis infection in dogs also had a lower DIC (805.2) compared with the non-spatial model (963.2) (Table 6). The prevalence of E. multilocularis infection was found to increase by $0.1 \%(95 \%$ CrI: $0.04-1.2 \%)$ with a 1 -unit increase in EVI.

In the model of dog infection with E. granulosus, the variance of the spatially structured random effect was $0.6(0.3$ to 1.0$)$ and in the model of dog infection with E. multilocularis this parameter was 1.6 (0.4 to 5.7$)$, meaning residual spatial variation was higher for the model of infection with $E$. multilocularis. The values of the
A

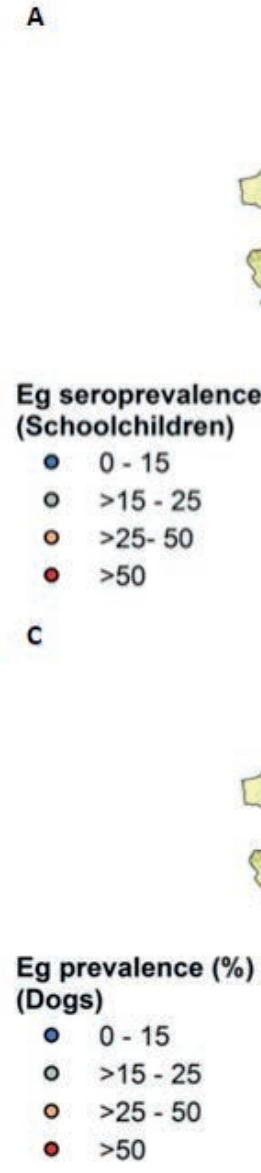

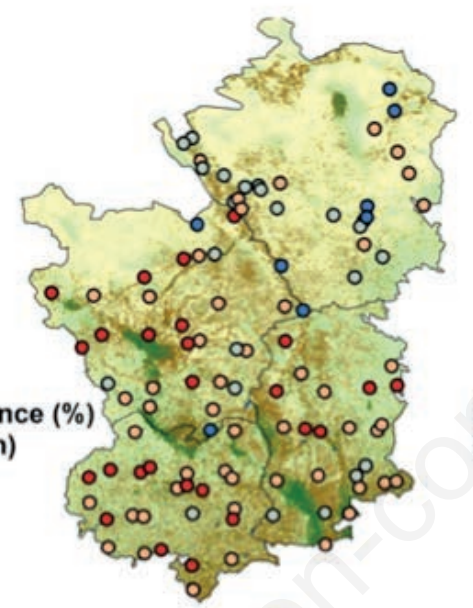

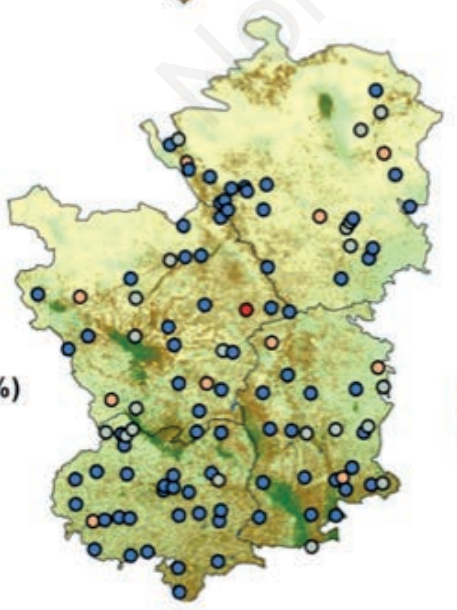

B

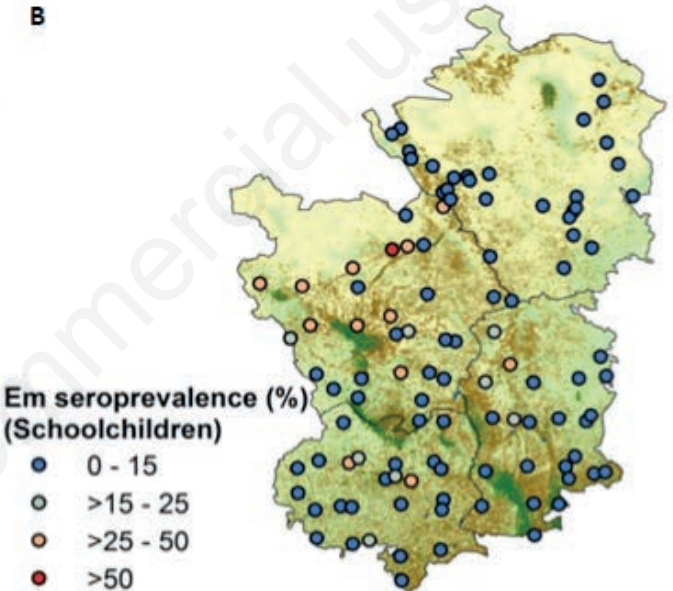

D

Em prevalence (\%) (Dogs)

- $0-15$

- >15-25

- $>25-50$

- $>50$

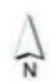

Land cover types

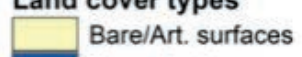
Water bodies Herbaceous vegetation Cultivated land Forest Shrubland

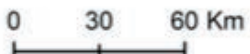

Figure 2. Distribution of surveys of E. granulosus and $E$. multilocularis exposure in schoolchildren and dogs and observed seroprevalence in 2012-2013 with locations of the different land cover types indicated in Xiji, Haiyuan, Guyuan and Tongxin counties, Ningxia Hui Autonomous Region, China. A) E. granulosus; B) E. multilocularis; C) infection with E. granulosus in dogs; D) infection with E. multilocularis in dogs. 
decay parameter for spatial correlation $(\phi)$ in the models of dog infection with E. granulosus and E. multilocularis were 69.4 and 41.2 , respectively, indicating that the radii of the clusters were larger for dog infection with E. granulosus than infection with $E$. multilocularis.

\section{Spatial predictions of human seroprevalence of E. granulosus and E. multilocularis}

The predictive risk maps of seroprevalence rates of E. granulosus and E. multilocularis in Xiji, Haiyuan, Guyuan and Tongxin Counties in 2012-2013 were created (Figure 3A and B). The highest seroprevalence of E. granulosus, $>60 \%$, was predicted for west-central Xiji and Haiyuan. However, E. granulosus seroprevalence rates between $40 \%$ and $60 \%$ were predicted in large areas throughout these two counties and in the central part of Guyuan. For most of the northern part of the study area, which corresponds to Tongxin county, low seroprevalence rates were predicted $(<40 \%)$. The highest seroprevalence of E. multilocularis, $>20 \%$, was found in a large area of the central part of Haiyuan county. In

Table 3. Regression coefficients, odd ratios and $95 \%$ CrI from Bayesian spatial model for seroprevalence of $E$. granulosus in schoolchildren in Xiji, Haiyuan, Tongxin and Guyuan counties in 2012-2013.

\begin{tabular}{|c|c|c|}
\hline Model & $\begin{array}{l}\text { Coefficient, } \\
\text { posterior mean } \\
\left(95 \% \mathrm{CrI}^{*}\right)\end{array}$ & $\begin{array}{l}\text { Odds ratios, } \\
\text { posterior mean } \\
(95 \% \mathrm{Cr})\end{array}$ \\
\hline Intercept & $\begin{array}{c}-0.68 \\
(-1.07 \text { to }-0.31)\end{array}$ & - \\
\hline Age & $\begin{array}{c}-4.2 \times 10^{-3} \\
(-0.03 \text { to } 0.02)\end{array}$ & $\begin{array}{c}0.99 \\
(0.97 \text { to } 1.02)\end{array}$ \\
\hline $\begin{array}{l}\text { Summer precipitation } \\
\text { same year }(5 \mathrm{~km})\end{array}$ & $\begin{array}{c}-1.83 \times 10^{-3} \\
\left(-7.98 \times 10^{-3} \text { to } 4.20 \times 10^{-3}\right)\end{array}$ & $\begin{array}{c}0.99 \\
\text { 3) }(0.99 \text { to } 1.01)\end{array}$ \\
\hline $\begin{array}{l}\text { Winter temperature } \\
5 \text { years prior }(1 \mathrm{~km})\end{array}$ & $\begin{array}{c}-0.07 \\
(-1.32 \text { to } 1.23)\end{array}$ & $\begin{array}{c}0.93 \\
(0.26 \text { to } 3.43)\end{array}$ \\
\hline $\begin{array}{l}\text { Winter temperature } \\
5 \text { years prior }(1 \mathrm{~km}) \text { squared }\end{array}$ & $\begin{array}{c}0.22 \\
(-0.17 \text { to } 0.59)\end{array}$ & $\begin{array}{c}1.24 \\
(0.84 \text { to } 1.80)\end{array}$ \\
\hline $\begin{array}{l}\text { Winter temperature } \\
\text { same year }(5 \mathrm{~km})\end{array}$ & $\begin{array}{c}-0.71 \\
(-2.00 \text { to } 0.68)\end{array}$ & $\begin{array}{c}0.49 \\
(0.13 \text { to } 1.99) \\
\end{array}$ \\
\hline $\begin{array}{l}\text { Winter temperature } \\
\text { same year }(5 \mathrm{~km}) \text { squared }\end{array}$ & $\begin{array}{c}-0.07 \\
(-0.27 \text { to } 0.13)\end{array}$ & $\begin{array}{c}0.92 \\
(0.76 \text { to } 1.14)\end{array}$ \\
\hline $\begin{array}{l}\text { Bare-land/Art. surfaces } \\
\text { same year }(1 \mathrm{~km})\end{array}$ & $\begin{array}{c}-0.01 \\
0.99\end{array}$ & $\begin{array}{c}\left.-0.01 \text { to }-4.02 \times 10^{-4}\right) \\
(0.98 \text { to } 0.99)\end{array}$ \\
\hline $\begin{array}{l}\text { Cultivated land } 5 \text { years } \\
\text { prior }(1 \mathrm{~km})\end{array}$ & $\begin{array}{c}-0.01 \\
\left(-0.01 \text { to } 3.63 \times 10^{-3}\right)\end{array}$ & $\begin{array}{c}0.99 \\
(0.98 \text { to } 1.00)\end{array}$ \\
\hline Forest 5 years prior $(1 \mathrm{~km})$ & $\begin{array}{c}-0.01 \\
(-0.04 \text { to } 0.02)\end{array}$ & $\begin{array}{c}0.99 \\
(0.95 \text { to } 1.02)\end{array}$ \\
\hline $\begin{array}{l}\text { Herbaceous vegetation } \\
\text { same year }(1 \mathrm{~km})\end{array}$ & $\begin{array}{c}3.24 \times 10^{-4} \\
(-0.01 \text { to } 0.01)\end{array}$ & $\begin{array}{c}0.99 \\
(0.98 \text { to } 1.01)\end{array}$ \\
\hline Scrubland same year (1 km) & $\begin{array}{c}-7.36 \\
(-16.43 \text { to } 1.73) \\
\end{array}$ & $\begin{array}{c}6.32 \times 10^{-4} \\
\left(7.26 \times 10^{-8} \text { to } 5.68\right)\end{array}$ \\
\hline Heterogeneity structured & $\begin{array}{c}0.58 \\
(0.36 \text { to } 0.99)\end{array}$ & - \\
\hline$\phi$ (Decay of spatial correlation) & $\begin{array}{c}20.89 \\
\text { (5.86 to } 71.23)\end{array}$ & - \\
\hline Deviance information criterion & 8,669 & - \\
\hline
\end{tabular}

northern Xiji and north-western Guyuan seroprevalence rates were between $8 \%$ and $16 \%$, while low seroprevalence rates of E. multilocularis, $0-6 \%$, were predicted for most of Tongxin and the southern part of Xiji County. Maps of the SDs of the posterior distributions of predicted seroprevalence rates of E. granulosus and $E$. multilocularis were also created (Figure $3 \mathrm{C}$ and D). The spatial distribution of high prediction uncertainty concurs with that of the areas with high seroprevalence rates of E. granulosus and E. multilocularis.

Table 4. Regression coefficients, odd ratios and 95\% CrI from Bayesian spatial model for seroprevalence of $E$. multilocularis in schoolchildren in Xiji, Haiyuan, Tongxin and Guyuan counties in 2012-2013.

\begin{tabular}{|c|c|c|}
\hline Model & $\begin{array}{l}\text { Coefficient, } \\
\text { posterior mean } \\
\left(95 \% \mathrm{CrI}^{*}\right)\end{array}$ & $\begin{array}{l}\text { Odds ratios, } \\
\text { posterior mean } \\
(95 \% \mathrm{Crl})\end{array}$ \\
\hline
\end{tabular}

Intercept

$-2.69$

$(-3.58$ to -1.88$)$

\begin{tabular}{lcc} 
Age & 0.03 & 1.03 \\
& $(-0.01$ to 0.07$)$ & $(0.99$ to 1.07$)$ \\
\hline Summer precipitation & 0.01 & 1.01 \\
5 years prior $(5 \mathrm{~km})$ & $(-0.01$ to 0.02$)$ & $(0.99$ to 1.02$)$ \\
Summer temperature & -3.32 & 0.03 \\
5 years prior $(5 \mathrm{~km})$ & $(-6.38$ to -0.28$)$ & $(0.01$ to 0.75$)$ \\
\hline Summer temperature & -1.96 & 0.14 \\
5 years prior $(5 \mathrm{~km})$ squared & $(-3.07$ to -0.81$)$ & $(0.04$ to 0.44$)$ \\
Winter temperature & -2.09 & 0.12 \\
5 years prior $(5 \mathrm{~km})$ & $(-5.20$ to 1.23$)$ & $(0.01$ to 3.44$)$ \\
\hline Winter temperature & 0.97 & 2.64 \\
5 years prior $(5 \mathrm{~km})$ & $(0.26$ to 1.68$)$ & $(1.30$ to 5.38$)$
\end{tabular}

squared

\begin{tabular}{|c|c|c|}
\hline $\begin{array}{l}\text { Bare-land/Art. surfaces } \\
5 \text { years prior }(5 \mathrm{~km})\end{array}$ & $\begin{array}{c}0.01 \\
(-0.02 \text { to } 0.03)\end{array}$ & $\begin{array}{c}1.00 \\
(0.98 \text { to } 1.03)\end{array}$ \\
\hline $\begin{array}{l}\text { Bare-land/Art. surfaces } \\
\text { same year }(5 \mathrm{~km})\end{array}$ & $\begin{array}{c}-0.01 \\
(-0.03 \text { to } 0.02)\end{array}$ & $\begin{array}{c}0.99 \\
(0.96 \text { to } 1.02)\end{array}$ \\
\hline $\begin{array}{l}\text { Cultivated land } \\
5 \text { years prior }(5 \mathrm{~km})\end{array}$ & $\begin{array}{c}0.01 \\
(-0.02 \text { to } 0.02)\end{array}$ & $\begin{array}{c}1.00 \\
(0.98 \text { to } 1.02)\end{array}$ \\
\hline Forest 5 years prior $(5 \mathrm{~km})$ & $\begin{array}{c}-0.01 \\
(-0.05 \text { to } 0.04)\end{array}$ & $\begin{array}{c}0.99 \\
(0.94 \text { to } 1.04)\end{array}$ \\
\hline Scrubland 5 years prior ( $5 \mathrm{~km})$ & $\begin{array}{c}-3.70 \\
(-8.05 \text { to } 0.47)\end{array}$ & $\begin{array}{c}0.02 \\
\left(3.00 \times 10^{-4} \text { to } 1.60\right)\end{array}$ \\
\hline Scrubland 5 same year $(5 \mathrm{~km})$ & $\begin{array}{c}-4.28 \\
(-10.81 \text { to } 2.16)\end{array}$ & $\begin{array}{c}0.01 \\
\left(0.02 \times 10^{-5} \text { to } 8.72\right)\end{array}$ \\
\hline Water bodies 5 years prior ( $5 \mathrm{~km}$ ) & $\begin{array}{c}0.89 \\
(-0.40 \text { to } 2.25)\end{array}$ & $\begin{array}{c}2.44 \\
0.66 \text { to } 9.52)\end{array}$ \\
\hline $\mathrm{EVI}^{* *} 5$ years prior $(1 \mathrm{~km})$ & $\begin{array}{l}-3.39 \times 10^{-4} \\
\left.01 \times 10^{-3} \text { to } 4.00 \times 10^{-4}\right)\end{array}$ & $\begin{array}{c}0.99 \\
(0.99 \text { to } 1.00)\end{array}$ \\
\hline EVI 5 years prior $(5 \mathrm{~km})$ & $\begin{aligned} & 1.80 \times 10-3 \\
&\left.0 \times 10^{-4} \text { to } 3.00 \times 10^{-3}\right)\end{aligned}$ & $\begin{array}{c}1.00 \\
(1.00 \text { to } 1.01)\end{array}$ \\
\hline Heterogeneity structured & $\begin{array}{c}1.18 \\
(0.71 \text { to } 1.91)\end{array}$ & - \\
\hline $\begin{array}{l}\phi \text { (Decay of spatial } \\
\text { correlation survey } 1 \text { ) }\end{array}$ & $\begin{array}{c}45.17 \\
\text { (11.74 to } 95.22)\end{array}$ & - \\
\hline Deviance information criterion & 3,575 & - \\
\hline
\end{tabular}

$* 95 \% \mathrm{Cr}, 95 \%$ credible interval; $* *$ enhanced vegetation index. 


\section{Spatial predictions of prevalence of dog infection with E. granulosus and E. multilocularis}

The highest predicted prevalence of dog infection with E. granulosus ( $>20 \%)$ was apparent in northern and eastern Haiyuan (Figure 4A). Almost all counties were predicted to be affected by this form of the infection except for Tongxin, where most of the territorial area had a predicted risk of $0-6 \%$. A large high-risk area of dog infection with E. multilocularis, $>0.20 \%$, was found in a region covering most of the south of the study area, which corresponds to the eastern part of Xiji and the south of Guyuan. More circumscribed areas of high risk of this infection in dogs were observed in the central part of Haiyuan. There was a large area of low risk, $0-6 \%$, in northeast Haiyuan and almost the entire territory of Tongxin (Figure 4B). The maps of predicted SDs also showed high prediction uncertainty in areas with high mean predicted risk (Figure 4C and D).

\section{Discussion}

This study presents detailed information on the predicted geographical distribution of the risk of seropositivity for E. granulosus and E. multilocularis among schoolchildren aged 6-18 years, and

Table 5. Regression coefficients, odd ratios and 95\% CrI from Bayesian spatial model for dog infection with $E$. granulosus in Xiji, Haiyuan, Tongxin and Guyuan counties in 2012-2013.

\begin{tabular}{|c|c|c|}
\hline Model & $\begin{array}{l}\text { Coefficient, } \\
\text { posterior mean } \\
\left(95 \% \mathrm{Cr}^{*}\right)\end{array}$ & $\begin{array}{l}\text { Odds ratios, } \\
\text { posterior mean } \\
(95 \% \mathrm{CrI})\end{array}$ \\
\hline Intercept & $\begin{array}{c}-2.38 \\
(-2.61 \text { to }-2.18)\end{array}$ & \\
\hline $\begin{array}{l}\text { Winter precipitation } \\
5 \text { years prior }(5 \mathrm{~km})\end{array}$ & $\begin{array}{c}-0.04 \\
(-0.11 \text { to } 0.01)\end{array}$ & $\begin{array}{c}0.95 \\
(0.89 \text { to } 1.01)\end{array}$ \\
\hline $\begin{array}{l}\text { Winter temperature } \\
5 \text { years prior }(1 \mathrm{~km})\end{array}$ & $\begin{array}{c}0.91 \\
\left(-4.40 \times 10^{-3} \text { to } 1.86\right)\end{array}$ & $\begin{array}{c}2.51 \\
(0.99 \text { to } 6.47)\end{array}$ \\
\hline $\begin{array}{l}\text { Bare-land/Art. surfaces } \\
5 \text { years prior }(5 \mathrm{~km})\end{array}$ & $\begin{array}{c}0.01 \\
\left(-4.40 \times 10^{-4} \text { to } 0.02\right)\end{array}$ & $\begin{array}{c}1.01 \\
(0.99 \text { to } 1.02)\end{array}$ \\
\hline $\begin{array}{l}\text { Cultivated land } \\
5 \text { years prior }(1 \mathrm{~km})\end{array}$ & $\begin{array}{c}0.02 \\
(0.01 \text { to } 0.03)\end{array}$ & $\begin{array}{c}1.02 \\
(1.01 \text { to } 1.03)\end{array}$ \\
\hline $\begin{array}{l}\text { Herbaceous vegetation } \\
5 \text { years prior }(5 \mathrm{~km})\end{array}$ & $\begin{array}{c}0.01 \\
\left(-3.10 \times 10^{-4} \text { to } 0.02\right)\end{array}$ & $\begin{array}{c}1.01 \\
(0.99 \text { to } 1.02)\end{array}$ \\
\hline $\begin{array}{l}\text { Scrubland } 5 \text { years } \\
\text { prior }(5 \mathrm{~km})\end{array}$ & $\begin{array}{c}-1.42 \\
(-3.68 \text { to } 0.87)\end{array}$ & $\begin{array}{c}0.24 \\
(0.02 \text { to } 2.41)\end{array}$ \\
\hline Water bodies same year ( $5 \mathrm{~km})$ & $\begin{array}{c}-0.16 \\
(-0.57 \text { to } 0.23)\end{array}$ & $\begin{array}{c}0.84 \\
(0.56 \text { to } 1.25)\end{array}$ \\
\hline $\mathrm{EVI}^{* *} 5$ years prior $(1 \mathrm{~km})$ & $\begin{array}{l}-5.51 \times 10^{-4} \\
\left.20 \times 10^{-3} \text { to } 1.00 \times 10^{-4}\right)\end{array}$ & $\begin{array}{c}0.99 \\
(0.99 \text { to } 1.00)\end{array}$ \\
\hline EVI 5 years prior $(5 \mathrm{~km})$ & $\begin{aligned} & 5.77 \times 10^{-4} \\
&\left.4 \times 10-5 \text { to } 1.15 \times 10^{-3}\right) \\
&\end{aligned}$ & $\begin{array}{c}1.00 \\
(1.00 \text { to } 1.01)\end{array}$ \\
\hline Heterogeneity structured & $\begin{array}{c}0.59 \\
(0.29 \text { to } 1.00)\end{array}$ & - \\
\hline$\phi$ (Decay of spatial correlation) & $\begin{array}{c}69.37 \\
\text { (25.85 to } 98.64)\end{array}$ & - \\
\hline Deviance information criterion & 2,121 & - \\
\hline
\end{tabular}

Table 6. Regression coefficients, odd ratios and 95\% CrI from Bayesian spatial model for dog infection with $E$. multilocularis in Xiji, Haiyuan, Tongxin and Guyuan counties in 2012-2013.

\begin{tabular}{|c|c|c|}
\hline Model & $\begin{array}{l}\text { Coefficient, } \\
\text { posterior mean } \\
\left(95 \% \mathrm{Cr}^{*}\right)\end{array}$ & $\begin{array}{l}\text { Odds ratios, } \\
\text { posterior mean } \\
(95 \% \mathrm{Crl})\end{array}$ \\
\hline Intercept & $\begin{array}{c}-4.09 \\
(-4.99 \text { to }-2.41)\end{array}$ & - \\
\hline $\begin{array}{l}\text { Annual temperature } \\
5 \text { years prior }(1 \mathrm{~km})\end{array}$ & $\begin{array}{c}-1.57 \\
(-17.50 \text { to } 9.6)\end{array}$ & $\begin{array}{c}0.20 \\
\left(2.50 \times 10^{-8} \text { to } 1.50 \times 10^{4}\right)\end{array}$ \\
\hline $\begin{array}{l}\text { Annual temperature } \\
\text { same year }(1 \mathrm{~km})\end{array}$ & $\begin{array}{c}-4.53 \\
(-19.58 \text { to } 10.08)\end{array}$ & $\begin{array}{c}0.01 \\
\left(3.10 \times 10^{-9} \text { to } 2.24 \times 10^{4}\right)\end{array}$ \\
\hline $\begin{array}{l}\text { Summer temperature } \\
5 \text { years prior }(5 \mathrm{~km})\end{array}$ & $\begin{array}{c}0.92 \\
(-9.78 \text { to } 14.50)\end{array}$ & $\begin{array}{c}2.52 \\
\left(5.61 \times 1^{0-5} \text { to } 1.99 \times 10^{6}\right)\end{array}$ \\
\hline $\begin{array}{l}\text { Summer temperature } \\
\text { same year }(5 \mathrm{~km})\end{array}$ & $\begin{array}{c}2.82 \\
(-8.75 \text { to } 13.49)\end{array}$ & $\begin{array}{c}16.89 \\
\left(1.57 \times 10^{-4} \text { to } 7.26 \times 10^{5}\right)\end{array}$ \\
\hline $\begin{array}{l}\text { Winter temperature } \\
5 \text { years prior }(1 \mathrm{~km})\end{array}$ & $\begin{array}{c}3.62 \\
(-12.59 \text { to 21.39) }\end{array}$ & $\begin{array}{c}37.65 \\
\left(3.38 \times 10^{-6} \text { to } 1.95 \times 10^{9}\right)\end{array}$ \\
\hline $\begin{array}{l}\text { Winter temperature } \\
5 \text { years prior }(1 \mathrm{~km}) \text { squared }\end{array}$ & $\begin{array}{c}0.85 \\
(-0.66 \text { to } 2.14)\end{array}$ & $\begin{array}{c}2.34 \\
(0.51 \text { to } 8.56)\end{array}$ \\
\hline $\begin{array}{l}\text { Winter temperature } \\
\text { same year }(1 \mathrm{~km})\end{array}$ & $\begin{array}{c}28.74 \\
(-4.27 \text { to } 56.02)\end{array}$ & $\begin{array}{c}3.02 \times 10^{12} \\
\left(0.01 \text { to } 2.13 \times 10^{24}\right)\end{array}$ \\
\hline $\begin{array}{l}\text { Winter temperature } \\
\text { same year }(1 \mathrm{~km}) \text { squared }\end{array}$ & $\begin{array}{c}4.42 \\
(-3.54 \text { to } 13.70)\end{array}$ & $\begin{array}{c}83.49 \\
\left(0.02 \text { to } 8.95 \times 10^{5}\right)\end{array}$ \\
\hline $\begin{array}{l}\text { Winter temperature } \\
5 \text { years prior }(5 \mathrm{~km})\end{array}$ & $\begin{array}{c}-0.28 \\
(-18.58 \text { to } 19.62)\end{array}$ & $\begin{array}{c}0.75 \\
\left.8.44 \times 10-9 \text { to } 3.33 \times 10^{8}\right)\end{array}$ \\
\hline $\begin{array}{l}\text { Winter temperature } \\
\text { same year }(5 \mathrm{~km})\end{array}$ & $\begin{array}{c}-28.97 \\
(-56.69 \text { to } 0.06)\end{array}$ & $\begin{array}{c}2.61 \times 10-13 \\
(2.37 \times 10-25 \text { to } 1.06)\end{array}$ \\
\hline $\begin{array}{l}\text { Winter temperature } \\
\text { same year }(5 \mathrm{~km}) \text { squared }\end{array}$ & $\begin{array}{c}-6.12 \\
(-16.11 \text { to } 2.11)\end{array}$ & $\begin{array}{c}2.22 \times 10^{-3} \\
(1.00 \times 10-7 \text { to } 8.26)\end{array}$ \\
\hline $\begin{array}{l}\text { Bare-land/Art surfaces } \\
5 \text { years prior }(5 \mathrm{~km})\end{array}$ & $\begin{array}{c}0.01 \\
(-0.01 \text { to } 0.03)\end{array}$ & $\begin{array}{c}1.01 \\
(0.98 \text { to } 1.03)\end{array}$ \\
\hline $\begin{array}{l}\text { Cultivated land } \\
5 \text { years prior }(5 \mathrm{~km})\end{array}$ & $\begin{array}{c}-6.01 \times 10^{-3} \\
(-0.03 \text { to } 0.02)\end{array}$ & $\begin{array}{c}0.99 \\
(0.95 \text { to } 1.02)\end{array}$ \\
\hline Forest same year (5 km) & $\begin{array}{l}-7.61 \times 10^{-3} \\
(-0.04 \text { to } 0.02)\end{array}$ & $\begin{array}{c}0.99 \\
(0.95 \text { to } 1.02)\end{array}$ \\
\hline $\begin{array}{l}\text { Herbaceous vegetation } \\
5 \text { years prior }(5 \mathrm{~km})\end{array}$ & $\begin{array}{l}-8.82 \times 10^{-3} \\
(-0.01 \text { to } 0.03)\end{array}$ & $\begin{array}{c}1.01 \\
\text { (0.98 to } 1.03)\end{array}$ \\
\hline Scrubland 5 years prior $(5 \mathrm{~km})$ & $\begin{array}{c}-4.60 \\
(-9.88 \text { to } 0.17)\end{array}$ & $\begin{array}{c}0.01 \\
\left(5.10 \times 10^{-5} \text { to } 1.19\right)\end{array}$ \\
\hline Scrubland same year (5 km) & $\begin{array}{c}-8.73 \\
(-26.85 \text { to } 3.63) \\
\end{array}$ & $\begin{array}{c}1.61 \times 10^{-4} \\
\left(2.17 \times 10^{-12} \text { to } 37.79\right)\end{array}$ \\
\hline $\begin{array}{l}\text { Water bodies } 5 \text { years } \\
\text { prior }(5 \mathrm{~km})\end{array}$ & $\begin{array}{c}-0.39 \\
(-2.06 \text { to } 1.08)\end{array}$ & $\begin{array}{c}0.67 \\
\text { (0.12 to } 2.95)\end{array}$ \\
\hline Elevation $(1 \mathrm{~km})$ & $\begin{array}{c}1.90 \times 10^{-3} \\
\left.8.37 \times 10^{-4} 4.80 \times 10^{-3}\right)\end{array}$ & $\begin{array}{c}1.00 \\
(0.99 \text { to } 1.00)\end{array}$ \\
\hline EVI $^{* *} 5$ years prior $(1 \mathrm{~km})$ & $\begin{aligned} & 6.84 \times 10^{-4} \\
& 0 \times 10^{-3} \text { to } 5.00 \times 10^{-4}\end{aligned}$ & $\begin{array}{c}0.99 \\
(0.99 \text { to } 1.00)\end{array}$ \\
\hline EVI 5 years prior $(5 \mathrm{~km})$ & $\begin{array}{l}1.00 \times 10^{-3} \\
\left.0 \times 10^{-5} \text { to } 1.97 \times 10^{-3}\right)\end{array}$ & $\begin{array}{c}1.00 \\
\text { (1.00 to } 1.00)\end{array}$ \\
\hline Heterogeneity structured & $\begin{array}{c}1.62 \\
(0.36 \text { to } 5.74)\end{array}$ & - \\
\hline$\phi$ (Decay of spatial correlation) & $\begin{array}{c}41.23 \\
\text { (1.14 to } 96.61)\end{array}$ & - \\
\hline Deviance information criterion & 805.2 & - \\
\hline
\end{tabular}

* 95\% CrI, 95\% credible interval; **enhanced vegetation index. 
infection with these parasites in dogs, in an important endemic area of PR China. To our knowledge, these are the first species-specific risk maps created for the region that concurrently reveal the spatial variation in echinococcosis risk for humans and dogs at a local spatial scale. Important climatic and land cover factors associated with the observed geographical heterogeneity in the risk of seropositivity were also identified. The findings are of current relevance in NHAR due to the ongoing process of landscape restoration in the Autonomous Region (Cadavid Restrepo et al., 2017; Li et al., 2013). Since 2002, the Grain for Green Project (GGP), a large national initiative to recover the degraded landscape, has been implemented in NHAR (Liu et al., 2008; Wang et al., 2007; Zhang et al., 2008). With the aim of reducing cropland on steep slopes, the GGP promotes three different types of land conversions: cropland to grassland, cropland to forest, and wasteland to forest (The University of Nottingham, 2010; Zhou et al., 2012). The project also advocates for desertification control and prohibition of enclo- sures for grazing practices (Wang et al., 2007). Studies conducted in other echinococcosis-endemic regions, where landscape transformation processes have taken place, indicate that some types of land cover change may have had an impact on the transmission patterns of E. multilocularis and, consequently, the risk of infection has increased for animals and humans (Craig et al., 2000; Giraudoux et al., 1998; Giraudoux et al., 2003).

This study demonstrated similarities in the spatial distribution of the predicted seroprevalence of E. granulosus among schoolchildren and infection in domestic dogs in the four counties in 2012-2013. Human seropositivity for E. granulosus was predicted for most of the study area, and dog infections with E. granulosus was predicted for almost all of Xiji County and in large areas of Haiyuan, Guyuan and Tongxin Counties. The North-Eastern and central parts of Tongxin were shown to have the lowest predicted prevalence of this parasite in humans and dogs. This geographical area of Tongxin is covered primarily by dry steppe vegetation and

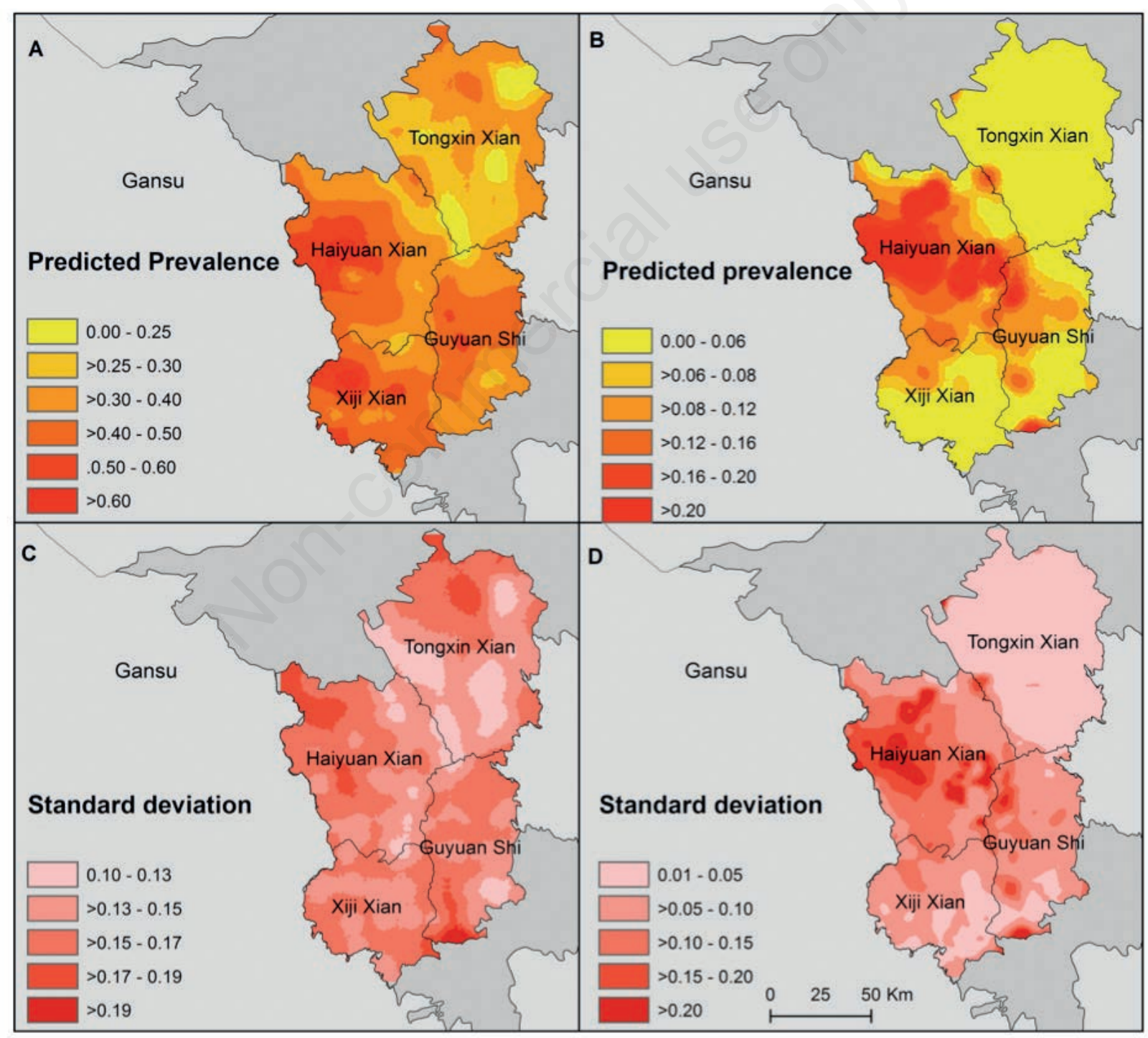

Figure 3. Spatial distribution of predicted seroprevalence rates of $E$. granulosus and $E$. multilocularis in schoolchildren aged 6-18 years in Xiji, Haiyuan, Guyuan and Tongxin counties, Ningxia Hui Autonomous Region, China in 2012-2013. A) E. granulosus; B) E. multilocularis; C) and D) corresponding standard deviations. 
desert grassland (Li et al., 2008). These characteristics of the local environment may be providing unfavourable ecological conditions for the transmission of E. granulosus, most probably due to the effects on the parasite eggs. Soil moisture/humidity and temperature particularly have been identified as important determinants of the survival and longevity of the Echinococcus spp. eggs in the external environment (Thevenet et al., 2005; Veit et al., 1995). Notably, the highest predicted prevalence of human seropositivity, unlike the highest predicted prevalence of dog infection, was found in areas from Xiji and Haiyuan Counties that share borders with the south of Gansu Province. In Gansu, human seropositivity and animal infections are also highly prevalent, with current estimates indicating that the annual incidence of human CE is between 2 and 10 cases per $10^{5}$ inhabitants (Deplazes et al., 2017). Therefore, the high predicted prevalence of human seropositivity for E. granulosus in these areas may be partially explained by the pastoral nomadic culture practices and the movement of people and domestic dogs across the provincial borders (Miller 2006; Shen 2012).

The geographical distribution of the predicted prevalence of $E$. multilocularis among the students did not concur with the distribution of the predicted prevalence of E. multilocularis infection in dogs. While high prevalence of human seropositivity for E. multilocularis was predicted for almost all Haiyuan County, high prevalence of dog infection with this species was predicted for the eastern Xiji and southern Guyuan Counties. Although this study involved a different population group, the finding in Xiji confirms the prediction of the distribution of human seropositivity for $E$. multilocularis conducted in the county in 2008, showing a similar geographical pattern (Pleydell et al., 2008). However, the findings do not support the current hypothesis that domestic dogs serve as the primary host of E. multilocularis in south NHAR (Budke et al., 2005a; Budke et al., 2005b; Romig et al., 2017). Dog ownership

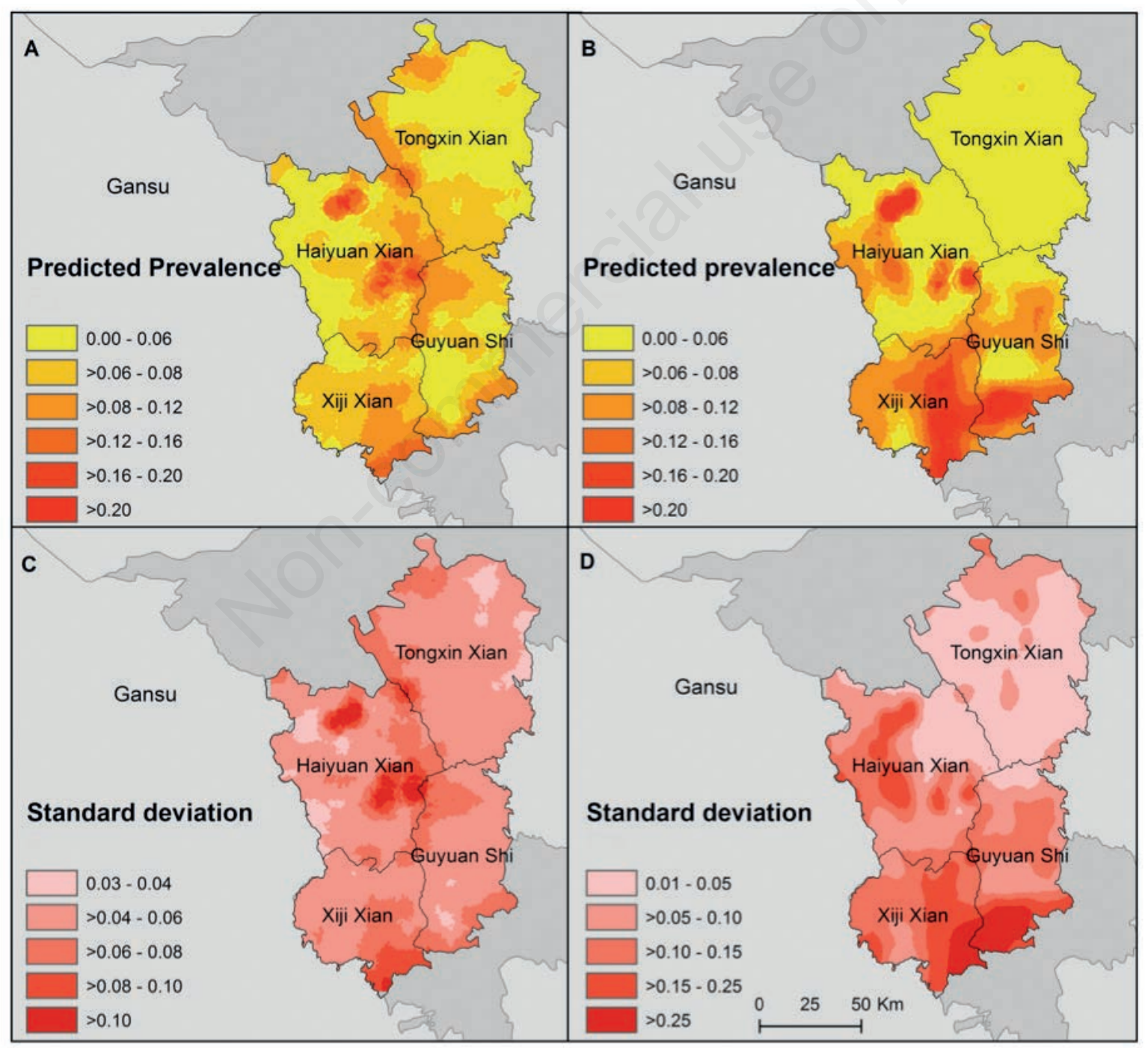

Figure 4. Spatial distribution of predicted prevalence rates of infection with E. granulosus and E. multilocularis in dogs in Xiji, Haiyuan, Guyuan and Tongxin counties, Ningxia Hui Autonomous Region, China in 2012-2013. A) E. granulosus; B) E. multilocularis; C) and D) corresponding standard deviations. 
and high levels of interaction between domestic dogs and humans are risk factors identified commonly in $\mathrm{AE}$ endemic-regions in north-western PR China (Craig et al., 2000; Craig, 2006; Schantz et al., 2003; Tiaoying et al., 2005), including NHAR (Yang et al., 2006c). High prevalence rates of dog infections with E. multilocularis have also been reported in highly endemic areas for $\mathrm{AE}$ (Budke et al., 2005a; Xiao et al., 2006; Ziadinov et al., 2010). Therefore, there is evidence that suggests dogs are an important reservoir of infections in humans (Romig et al., 2017). However, the observed differences in the geographical distribution of the predicted prevalence of the infection in both hosts may suggest greater importance of other definitive host species in transmitting the parasite in the south of NHAR. The transmission of E. multilocularis through life cycles that involve both Tibetan sand foxes (Vulpes ferrilata) and domestic dogs has been reported in Sichuan Province (Vaniscotte et al., 2011). Similar transmission patterns have been described in areas of the Altai, Tien Shan and Pamir mountains in the south of Kyrgyzstan and Kazakhstan (Ziadinov et al., 2008; Ziadinov et al., 2010). There, red foxes ( $V$. vulpes) were identified as principal definitive hosts, while domestic dogs were identified secondary definitive hosts of E. multilocularis (Ziadinov et al., 2008; Ziadinov et al., 2010). Reports of infection with $E$. multilocularis in red foxes in NHAR are only available for the mid-1980's (Li W et al., 1985). At that time, 15\% of trapped red foxes were infected with E. multilocularis in Xiji and Guyuan Counties (Li W et al., 1985). Although infection with E. multilocularis has also been described in wolves (Canis lupus) and corsac foxes (V.corsac) in other parts of PR China (Craig et al., 2000), corsac and red foxes are presumed absent in areas of high risk of human AE in Xiji County (Giraudoux et al., 2013a). Hence, there is still a need for a more holistic approach that can help identify other important predator-prey communities in the area and other potential key definitive host for this parasite species in the region.

The results indicate that differences in vegetation, as indicated by EVI values, played a key role in explaining the observed spatial variation in the seropositivity for $E$. multilocularis among children aged 6-18 years, and infections with E. granulosus and E. multilocularis in dogs in the four counties. In addition, a positive association was found between dog infection with E. granulosus and cultivated land and a negative association between human seropositivity for E. granulosus and bare-land/artificial surfaces. Associations between land cover and the spatial distribution of $E$. multilocularis seropositivity in humans and intermediate hosts are well documented in Eastern France, South Gansu, western Sichuan and Qinghai Provinces and in the South of NHAR (Giraudoux et al., 2003; Giraudoux et al., 2006; Giraudoux et al., 2013b; Pleydell et al., 2008; Wang et al., 2004; Wang et al., 2006). The previous study conducted in Xiji County indicated that the abundance of degraded lowland pasture was associated with a higher prevalence of AE in humans (Pleydell et al., 2008). The presence of 16 species of small mammals communities was also revealed in a survey of small-mammal conducted in relation to different land cover types in the same area (Raoul et al., 2008). That survey also showed that in areas that experienced afforestation, species diversity was lower than that in deforested areas (Raoul et al., 2008). However, the richness of the species was not affected by land conversion processes (Raoul et al., 2008). In abandoned grasslands and recently afforested set-aside fields, there was higher trapping success of potential intermediate hosts for E. multilocularis such as Cricetulus longicaudatus and Ochotona daurica, while in young plantations the species Spermophilus alashanicus/dauricus were observed (Raoul et al., 2008). Reports of the link between foxes and the landscape in France are available (Pleydell et al., 2004). The evidence indicates that these associations are based on the influence of specific ecology characteristics on intermediate host population dynamics (Giraudoux et al., 2013a).

With regard to climatic covariates, the observed non-linear relationship between human $\mathrm{AE}$ prevalence and the values of winter and summer temperatures at the 5 years prior to the survey are consistent and interpretable with animal population dynamics, predator-prey interactions and the biology of the parasites. Temperature has been identified as a contributing factor that affects the geographical range and composition of foxes and small mammal communities (Hersteinsson and Macdonald, 1992; Moritz et al., 2008; Zhenghuan et al., 2008). Experimental studies indicate that the Echinococcus spp. eggs develop at temperaturedependent rates in the external environment (Veit et al., 1995). The optimal temperature range for their survival has been established to be between $0{ }^{\circ} \mathrm{C}$ and $10{ }^{\circ} \mathrm{C}$ (Veit et al., 1995). However, differences have been found between species and strains (Thevenet et al., 2005; Veit et al., 1995). Temperatures of $4{ }^{\circ} \mathrm{C}$ and of $-18{ }^{\circ} \mathrm{C}$ particularly, are well tolerated by E. multilocularis eggs with survival times of 478 and 240 days, respectively (Veit et al., 1995). Also, the evidence show that these eggs, if suspended in water, can remained infectious for a longer time than when exposed to heat (Federer et al., 2015).

Current estimates of the burden of human echinococcoses in NHAR rely primarily on data collected from hospital records (Yang et al., 2006b; Yang et al., 2006c). These data include primarily symptomatic patients who seek medical care (Yang et al., 2006a; Yang et al., 2006b). Therefore, it is assumed that the extent and distribution of human $\mathrm{CE}$ and $\mathrm{AE}$ cases occurring in remote areas and asymptomatic infections may be underestimated in current epidemiological reports (Yang et al., 2006b). In 2005, the National Control Programme against echinococcoses was developed by the National Health and Family Planning Commission (formerly the Ministry of Health) in PR China. The measures that are currently being implemented in endemic areas include: community-based epidemiological surveys for early detection, treatment and surveillance of the disease, education campaigns to increase awareness among local people and health officials, and regular anthelmintic treatment for deworming of dogs (World Health Organization and World Organisation for Animal Health, 2011; Yang et al., 2006c). Prevalence data on these infections are essential for enhancing these control activities and monitoring their cost-effectiveness and sustainability over time. Therefore, the findings of this study indicate that there is scope for the predictive maps created here to inform and guide spatially targeted interventions in those areas where they are most necessary. An additional benefit of this type of approach is that the maps allow monitoring of the transmission patterns of E. granulosus and E. multilocularis based on local environmental factors. In this way, it is possible to provide detailed information on the potential health effects of anthropogenic environmental change factors, including those that are associated with the implementation of national policies to recover the degraded landscape.

An important limitation of the study was the use of specific antibody testing by enzyme linked immunosorbent assay using $E$. granulosus cyst fluid antigen B and E. multilocularis crude protoscolex extract to define seropositivity of schoolchildren to E. granulosus and/or E. multilocularis. These tests have poor diagnostic performance with limited specificity and cross-reactivity with 
other helminth infections and gastrointestinal malignancies (Brunetti et al., 2010; Torgerson et al., 2009). However, serology, although not ideal, is the only diagnostic method available for small echinococcosis lesions that are probably asymptomatic. Therefore, follow-up examination is recommended to confirm the infections.

\section{Conclusions}

This work provides detailed information regarding the geographical distribution of echinococcoses in humans and dogs in NHAR. The different models developed in this study indicate that human seropositivity for E. granulosus and dog infection with $E$. granulosus are widespread across the southern part of the Autonomous Region. Discrepancies in the geographical distribution of human seropositivity for E. multilocularis and dog infection with $E$. multilocularis suggest that further research is required to better understand the transmission dynamics of this parasite species. The results presented help to identify priority areas for echinococcosis control and may be used to target interventions where they have the greatest impact on the transmission of the infections.

\section{References}

Ammann RW, Eckert J, 1996. Cestodes. Echinococcus. Gastroenterol Clin North Am 25:655-89.

Atkinson JAM, Gray DJ, Clements AC, Barnes TS, McManus DP, Yang YR, 2013. Environmental changes impacting echinococcus transmission: Research to support predictive surveillance and control. Glob Chang Biol 19:677-88.

Bartholomot G, Vuitton DA, Harraga S, Shi DZ, Giraudoux P, Barnish G, Wang YH, MacPherson CNL, Craig PS, 2002. Combined ultrasound and serologic screening for hepatic alveolar echinococcosis in central China. Am J Trop Med Hyg 66:239.

Brunetti E, Kern P, Vuitton DA, 2010. Expert consensus for the diagnosis and treatment of cystic and alveolar echinococcosis in humans. Acta Trop 114:1-16.

Brunetti E, Garcia HH, Junghanss T, 2011. Cystic echinococcosis: Chronic, complex, and still neglected. PLoS Negl Trop Dis 5:e1146.

Budke CM, Campos-Ponce M, Qian W, Torgerson PR, 2005a. A canine purgation study and risk factor analysis for echinococcosis in a high endemic region of the Tibetan Plateau. Vet Parasitol 127:43-9.

Budke CM, Jiamin Q, Craig PS, Torgerson PR, 2005b. Modeling the transmission of Echinococcus granulosus and Echinococcus multilocularis in dogs for a high endemic region of the Tibetan Plateau. Int J Parasitol 35:163-70.

Cadavid Restrepo AM, Yang Y, McManus D, Gray D, Giraudoux P, Barnes T, Williams G, Soares MR, Hamm N, Clements A, 2015. The landscape epidemiology of echinococcoses. Infect Dis Poverty 5:13.

Cadavid Restrepo AM, Yang YR, Hamm NA, Gray DJ, Barnes TS, Williams GM, Magalhães RJS, McManus DP, Guo D, Clements AC, 2017. Land cover change during a period of extensive landscape restoration in ningxia hui autonomous region, China. Sci
Total Environ 598:669-79.

Carmena D, Benito A, Eraso E, 2006. Antigens for the immunodiagnosis of Echinococcus granulosus infection: An update. Acta Trop 98:74-86.

Craig P, Liu D, Shi D, Macpherson C, Barnish G, Reynolds D, Gottstein B, Wang Z, 1992. A large focus of alveolar echinococcosis in central China. Lancet 340:826-31.

Craig P, Giraudoux P, Shi D, Bartholomot B, Barnish G, Delattre P, Quere J, Harraga S, Bao G, Wang Y, 2000. An epidemiological and ecological study of human alveolar echinococcosis transmission in south Gansu, China. Acta Trop 77:167-77.

Craig P, Hegglin D, Lightowlers M, Torgerson P, Wang Q, 2017. Chapter two-echinococcosis: Control and prevention. Adv Parasitol 96:55-158.

Craig PS, 2006. Epidemiology of human alveolar echinococcosis in China. Parasitol Int 55:S221-5.

Cringoli G, Rinaldi L, Musella V, Veneziano V, Maurelli MP, Di Pietro F, Frisiello M, Di Pietro S, 2007. Geo-referencing livestock farms as tool for studying cystic echinococcosis epidemiology in cattle and water buffaloes from southern Italy. Geospat Health 2:105-11.

Danson F, Graham A, Pleydell D, Campos-Ponce M, Giraudoux P, Craig P, 2003. Multi-scale spatial analysis of human alveolar echinococcosis risk in China. Parasitology 127:S133-41.

Deplazes P, Rinaldi L, Rojas CA, Torgerson P, Harandi M, Romig T, Antolova D, Schurer J, Lahmar S, Cringoli G, 2017. Chapter six-global distribution of alveolar and cystic echinococcosis. Adv Parasitol 95:315-493.

Diggle P, Ribeiro PJ, 2007. Model-based geostatistics. New York, NY: Springer; 2007. pp 199-212.

DIVA GIS, Diva-gis: Free, simple \& effective. Available from: http://www.diva-gis.org/.

Eckert J, 2001. WHO/OIE manual on echinococcosis in humans and animals: A public health problem of global concern. Available from:http://www. Who.Int/echinococcosis/resources/9290 44522x/en/.

Eckert J, Deplazes P, 2004. Biological, epidemiological, and clinical aspects of echinococcosis, a zoonosis of increasing concern. Clin Microbiol Rev 17:107-35.

ESRI, 2015. Environmental systems research institute. ArcGIS software version 10.3.1. Redlands. California.

Federer K, Armua-Fernandez MT, Hoby S, Wenker C, Deplazes P, 2015. In vivo viability of Echinococcus multilocularis eggs in a rodent model after different thermo-treatments. Exp Parasitol 154:14-9.

Giraudoux P, Bao G, Craig P, Delattre P, Quéré J-P, Shi D, Vuitton D, Wang X, 1998. Distribution of small mammals along a deforestation gradient in southern Gansu, central China. Acta Theriol Sin 43:349-62.

Giraudoux P, Craig P, Delattre P, Bao G, Bartholomot B, Harraga S, Quéré J-P, Raoul F, Wang Y, Shi D, 2003. Interactions between landscape changes and host communities can regulate Echinococcus multilocularis transmission. Parasitology 127:S121-31.

Giraudoux P, Pleydell D, Raoul F, Quéré J-P, Wang Q, Yang Y, Vuitton DA, Qiu J, Yang W, Craig PS, 2006. Transmission ecology of Echinococcus multilocularis: What are the ranges of parasite stability among various host communities in China? Parasitol Int 55:S237-46.

Giraudoux P, Pleydell D, Raoul F, Vaniscotte A, Ito A, Craig PS, 2007. Echinococcus multilocularis: Why are multidisciplinary 
and multiscale approaches essential in infectious disease ecology? Trop Med Health 35:293.

Giraudoux P, Raoul F, Afonso EVE, Ziadinov I, Yang Y, Li LI, Li T, Quéré J-P, Feng X, Wang Q, Wen HAO, Ito A, Craig PS, Ito A, Zhou X-N, Craig PS, Giraudoux P, 2013a. Transmission ecosystems of Echinococcus multilocularis in China and central Asia. Parasitology 140:1655-66.

Giraudoux P, Raoul F, Pleydell D, Li T, Han X, Qiu J, Xie Y, Wang H, Ito A, Craig PS, 2013b. Drivers of Echinococcus multilocularis transmission in china: Small mammal diversity, landscape or climate? PLoS Negl Trop Dis 7:e2045.

Hersteinsson P, Macdonald DW, 1992. Interspecific competition and the geographical distribution of red and arctic foxes vulpes vulpes and alopex lagopus. Oikos 64:505-15.

Kapel CM, Torgerson P, Thompson R, Deplazes P, 2006. Reproductive potential of Echinococcus multilocularis in experimentally infected foxes, dogs, raccoon dogs and cats. Int J Parasitol 36:79-86.

Kern P, Wen H, Sato N, Vuitton DA, Gruener B, Shao Y, Delabrousse E, Kratzer W, Bresson-Hadni S, 2006. Who classification of alveolar echinococcosis: Principles and application. Parasitol Int 55:S283-7.

Kern P, da Silva AM, Akhan O, Müllhaupt B, Vizcaychipi K, Budke C, Vuitton D, 2017. Chapter four-the echinococcoses: Diagnosis, clinical management and burden of disease. Adv Parasitol 96:259-369.

Li J, Zheng G, Liu H, Wang L, Tang Z, Shi H, Guo W, Wang H, 2008. Situation analysis of Ningxia province. In: China Climate Change Partnership Framework - Enhanced strategies for climate-proofed and environmentally sound agricultural production in the Yellow River Basin (C-PESAP). Available from:

http://wwwfaoorg/fileadmin/templates/cpesap/Data/Ningxia/SASNi ngxiawppdf

Li W, Zhang G, Lin YLH, 1985. The occurrence of Echinococcus multilocularis leukart, 1863 the natural animal host in china and its morphological study. Acta Zoo Sin 1985:365-70.

Li Y, Conway D, Wu Y, Gao Q, Rothausen S, Xiong W, Ju H, Lin E, 2013. Rural livelihoods and climate variability in Ningxia, northwest China. Clim Change 119:891-904.

Liu CN, Lou ZZ, Li L, Yan HB, Blair D, Lei MT, Cai JZ, Fan YL, Li JQ, Fu BQ, 2015. Discrimination between E. granulosus sensu stricto, E. multilocularis and E. shiquicus using a multiplex PCR assay. PLoS Negl Trop Dis 9:e0004084.

Liu J, Li S, Ouyang Z, Tam C, Chen X, 2008. Ecological and socioeconomic effects of China's policies for ecosystem services. Proc Natl Acad Sci USA 105:9477-82.

Marston CG, Giraudoux P, Armitage RP, Danson FM, Reynolds SC, Wang Q, Qiu J, Craig PS, 2016. Vegetation phenology and habitat discrimination: Impacts for E. multilocularis transmission host modelling. Remote Sens Environ 176:320-7.

Mastin A, Brouwer A, Fox M, Craig P, Guitián J, Li W, Stevens K, 2011. Spatial and temporal investigation of Echinococcus granulosus coproantigen prevalence in farm dogs in south powys, wales. Vet Parasitol 178:100-7.

McManus DP, Ding Z, Bowles J, 1994. A molecular genetic survey indicates the presence of a single, homogeneous strain of Echinococcus granulosus in north-western China. Acta Trop 56:7-14.

McManus DP, Gray DJ, Zhang W, Yang Y, 2012. Diagnosis, treatment, and management of echinococcosis. BMJ 344:39-44.

Members of OpenBUGS Project Management Group, 2014.
Openbugs software version 3.2.2 rev 1012 .

Miller DJ, 2006. Nomads of the tibetan plateau rangelands in western China. I. Pastoral history. Rangelands Archiv 20:24-9.

Moritz C, Patton JL, Conroy CJ, Parra JL, White GC, Beissinger SR, 2008. Impact of a century of climate change on small-mammal communities in Yosemite National Park, USA. Science 322:2614.

Moss J, Chen X, Li T, Qiu J, Wang Q, Giraudoux P, Ito A, Torgerson P, Craig P, 2013. Reinfection studies of canine echinococcosis and role of dogs in transmission of Echinococcus multilocularis in Tibetan communities, Sichuan, China. Parasitology 140:1685-92.

National Bureau of Statistics of China, 2015. Population data. Available from: Http://data.Stats.Gov.Cn/english/ easyquery. $\mathrm{Htm} ? \mathrm{Cn}=\mathrm{c} 01$.

Pleydell D, Raoul F, Tourneux F, Danson F, Graham A, Craig P, Giraudoux P, 2004. Modelling the spatial distribution of Echinococcus multilocularis infection in foxes. Acta Trop 91:253-65.

Pleydell DR, Yang YR, Danson FM, Raoul F, Craig PS, McManus DP, Vuitton DA, Wang Q, Giraudoux P, 2008. Landscape composition and spatial prediction of alveolar echinococcosis in southern Ningxia, China. PLoS Negl Trop Dis 2:e287.

R Core Team, 2015. R: A language and environment for statistical computing. $\mathrm{R}$ foundation for statistical computing, Vienna, Austria. Available from: https://www.R-project.Org/.

Raoul F, Quéré J-P, Rieffel D, Bernard N, Takahashi K, Scheifler R, Ito A, Wang Q, Qiu J, Yang W, 2006. Distribution of small mammals in a pastoral landscape of the tibetan plateaus (western Sichuan, China) and relationship with grazing practices. Mammalia 70:214-25.

Raoul F, Pleydell D, Quere J-P, Vaniscotte A, Rieffel D, Takahashi K, Bernard N, Wang J, Dobigny T, Galbreath KE, 2008. Smallmammal assemblage response to deforestation and afforestation in central China. Mammalia 72:320-32.

Rausch R, 1995. Life cycle patterns and geographic distribution of Echinococcus species. Echinococcus and hydatid disease. Wallingford: CAB International, pp 89-134.

Romig T, Deplazes P, Jenkins D, Giraudoux P, Massolo A, Craig PS, Wassermann M, Takahashi K, De La Rue M, 2017. Chapter fiveecology and life cycle patterns of Echinococcus species. Adv Parasitol 95:213-314.

Schantz P, Wang H, Qiu J, Liu F, Saito E, Emshoff A, Ito A, Roberts J, Delker C, 2003. Echinococcosis on the Tibetan Plateau: Prevalence and risk factors for cystic and alveolar echinococcosis in Tibetan populations in Qinghai province, China. Parasitology 127:S109-20.

Shen J, 2012. Changing patterns and determinants of interprovincial migration in China 1985-2000. Popul Space Place 18:384-402.

Silva M, Hartling L, Opps SB, 2005. Small mammals in agricultural landscapes of Prince Edward Island (Canada): Effects of habitat characteristics at three different spatial scales. Biol Conserv 126:556-68.

The National Aeronautics and Space Administration (NASA) and Ministry of Economy Trade and Industry (METI), The advanced spaceborne thermal emission and reflection radiometer (aster) global digital elevation model (GDEM). Version 2. Aster GDEM is a product of NASA and METI. Available from: https://asterweb.Jpl.Nasa.Gov/gdem.Asp.

The United States Geological Survey (USGS), Earthexplorer. Available from: http://earthexplorer.usgs.gov. 
The United States Geological Survey (USGS), Earth resources observation and science (EROS) center science processing architecture (ESPA) on demand interface. Available from: https://espa.cr.usgs.gov/.

The University of Nottingham, 2010. China policy institute. 'Grain for green programme' in China: Policy making and implementation? Briefing series, 60. Available from: http://www.nottingham.ac.uk/cpi/documents/briefings/briefing-60-reforestation.Pdf.

Thevenet PS, Jensen O, Drut R, Cerrone GE, Grenóvero MS, Alvarez HM, Targovnik HM, Basualdo JA, 2005. Viability and infectiousness of eggs of Echinococcus granulosus aged under natural conditions of inferior arid climate. Vet Parasitol 133:717.

Tiaoying L, Jiamin Q, Wen Y, Craig PS, Xingwang C, Ning X, Ito A, Giraudoux P, Wulamu M, Wen Y, 2005. Echinococcosis in Tibetan populations, western Sichuan province, China. Emerg Infect Dis 11:1866-73.

Torgerson PR, Rosenheim K, Tanner I, Ziadinov I, Grimm F, Brunner M, Shaiken S, Shaikenov B, Rysmukhambetova A, Deplazes P, 2009. Echinococcosis, toxocarosis and toxoplasmosis screening in a rural community in eastern Kazakhstan. Trop Med Int Health 14:341-8.

Torgerson PR, Keller K, Magnotta M, Ragland N, 2010. The global burden of alveolar echinococcosis. PLoS Negl Trop Dis 4:e722.

Torgerson PR, Devleesschauwer B, Praet N, Speybroeck N, Willingham AL, Kasuga F, Rokni MB, Zhou X-N, Fèvre EM, Sripa B, 2015. World Health Organization estimates of the global and regional disease burden of 11 foodborne parasitic diseases, 2010: A data synthesis. PLoS Med 12:e1001920.

Vaniscotte A, Raoul F, Poulle M-L, Romig T, Dinkel A, Takahashi K, Guislain M-H, Moss J, Tiaoying L, Wang Q, 2011. Role of dog behaviour and environmental fecal contamination in transmission of Echinococcus multilocularis in Tibetan communities. Parasitology 138:1316-29.

Veit P, Bilger B, Schad V, Schäfer J, Frank W, Lucius R, 1995. Influence of environmental factors on the infectivity of Echinococcus multilocularis eggs. Parasitology 110:79-86.

Wang Q, Vuitton DA, Qiu J, Giraudoux P, Xiao Y, Schantz PM, Raoul F, Li T, Yang W, Craig PS, 2004. Fenced pasture: A possible risk factor for human alveolar echinococcosis in Tibetan pastoralist communities of Sichuan, China. Acta Trop 90:28593.

Wang Q, Qiu J, Yang W, Schantz PM, Raoul F, Craig PS, Giraudoux $\mathrm{P}$, Vuitton DA, 2006. Socioeconomic and behavior risk factors of human alveolar echinococcosis in Tibetan communities in Sichuan, People's Republic of China. Am J Trop Med Hyg 74:856-62.

Wang Q, Raoul F, Budke C, Craig PS, Xiao Y-f, Vuitton DA, Campos-Ponce M, Qiu D-C, Pleydell D, Giraudoux P, 2010. Grass height and transmission ecology of Echinococcus multilocularis in Tibetan communities, China. Chin Med J 123:61.

Wang X, Lu C, Fang J, Shen Y, 2007. Implications for development of grain-for-green policy based on cropland suitability evaluation in desertification-affected north China. Land Use Policy 24:417-24.

WHO Informal Working Group, 2003. International classification of ultrasound images in cystic echinococcosis for application in clinical and field epidemiological settings. Acta Trop 85:253-61.

WHO Informal Working Group on Echinococcosis, 2001. Pair:
Puncture, aspiration, injection, re-aspiration. An option for the treatment of cystic echinococcosis. Available from: http://apps.Who.Int/iris/bitstream/10665/67207/1/who_cds_csr _aph_2001.6.Pdf.

World Health Organization and World Organisation for Animal Health, 2011. Report of the WHO informal working group on cystic and alveolar echinococcosis surveillance, prevention and control, with the participation of the food and agriculture organization of the United Nations and the World Organisation for Animal Health. Available from: http://apps.who.int/iris/bitstream/10665/44785/1/9789241502924_eng.pdf.

Xiao N, Nakao M, Qiu J, Budke CM, Giraudoux P, Craig PS, Ito A, 2006. Dual infection of animal hosts with different Echinococcus species in the eastern Qinghai-Tibet Plateau region of China. Am J Trop Med Hyg 75:292-4.

Yang Y, Rosenzvit M, Zhang L, Zhang J, McManus D, 2005. Molecular study of Echinococcus in west-central China. Parasitology 131:547-55.

Yang YR, Cheng L, Yang SK, Pan X, Sun T, Li X, Hu S, Zhao R, Craig PS, Vuitton DA, McManus DP, 2006a. A hospital-based retrospective survey of human cystic and alveolar echinococcosis in Ningxia Hui Autonomous Region, PR China. Acta Trop 97:284-91.

Yang YR, Sun T, Li Z, Zhang J, Teng J, Liu X, Liu R, Zhao R, Jones MK, Wang Y, 2006b. Community surveys and risk factor analysis of human alveolar and cystic echinococcosis in Ningxia Hui Autonomous Region, China. Bull World Health Organ 84:71421.

Yang YR, Williams G, Craig P, Sun T, Yang S, Cheng L, Vuitton D, Giraudoux P, Li X, Hu S, 2006c. Hospital and community surveys reveal the severe public health problem and socio $\square$ economic impact of human echinococcosis in Ningxia Hui Autonomous Region, China. Trop Med Int Health 11:880-8.

Yang YR, Craig PS, Vuitton DA, Williams GM, Sun T, Liu TX, Boufana B, Giraudoux P, Teng J, Li Y, Huang L, Zhang W, Jones MK, McManus DP, 2008. Serological prevalence of echinococcosis and risk factors for infection among children in rural communities of southern Ningxia, China. Trop Med Int Health 13:1086-94

Zhang L, Tu Q, Mol AP, 2008. Payment for environmental services: The sloping land conversion program in Ningxia Autonomous Region of China. China World Econ 16:66-81.

Zhenghuan W, Xiaoming W, Xiaoqing L, 2008. Echinococcosis in China, a review of the epidemiology of Echinococcus spp. EcoHealth 5:115-26.

Zhou D, Zhao S, Zhu C, 2012. The grain for green project induced land cover change in the loess plateau: A case study with Ansai county, Shanxi province, China. Ecol Indic 23:88-94.

Ziadinov I, Mathis A, Trachsel D, Rysmukhambetova A, Abdyjaparov TA, Kuttubaev OT, Deplazes P, Torgerson PR, 2008. Canine echinococcosis in kyrgyzstan: Using prevalence data adjusted for measurement error to develop transmission dynamics models. Int J Parasitol 38:1179-90.

Ziadinov I, Deplazes P, Mathis A, Mutunova B, Abdykerimov K, Nurgaziev R, Torgerson P, 2010. Frequency distribution of Echinococcus multilocularis and other helminths of foxes in Kyrgyzstan. Vet Parasitol 171:286-92. 